\title{
Laparoscopic appendicectomy in higher grades of appendicitis
}

\author{
Srigireesh A $R^{1}$, Natarajan $R^{2}$, Karunanithi $R^{3}$, Balakrishnan $V^{4}$, Loganathan $M^{5}$ \\ ${ }^{1}$ Dr. Srigireesh A R, Post Graduate, ${ }^{2}$ Dr. Natarajan R, Assistant Professor, ${ }^{3}$ Dr. Karunanithi R, Professor, ${ }^{4}$ Dr. Balakrishnan \\ V, Professor, ${ }^{5}$ Dr. Loganathan M, Professor, All authors are affiliated with Chettinad Academy of research and Education, \\ Chennai.
}

Address for Correspondence: Dr. Srigireesh A R, Post-graduate. Email: dr.srigireesh@gmail.com

\begin{abstract}
Introduction: Complicated appendicitis has higher morbidity and mortality than non-complicated appendicitis. Despite of many clinical studies and meta-analyses of the various studies it remains confusion for the surgeons to decide which approach, whether Open (OA) or Laparoscopic Appendicectomy (LA) is the most efficacious and effective for complicated appendicitis. This is because, earlier studies reported the occurrence of post-operative complication like intraabdominal abscess following LA. Objectives: Primary: 1) To evaluate the results of laparoscopic appendicectomy in various grades complicated appendicitis. (Grade III, IV, V). Secondary- 2) To find out the percentage of postoperative complications. 3) To compare the post-operative pain among three grades of complicated appendicitis. Methodology: Patients with clinical suspicion of complicated appendicitis underwent blood and imaging investigations and Alvarado's scoring was done and patients with very probable appendicitis were subjected for laparoscopy and grading of appendicitis will be done and Grade III, IV, V patients will be included in our study and their peri-operative parameters will be analysed and compared among the three grades of appendicitis. Results: In 46 patients LA was performed. 4(8\%) patients needed conversion. We had 47.83\%, $32.61 \%$ and $19.57 \%$ of Grade III, IV V patients respectively. Mean operative time and hospital stay were 68.8 mins and 3.91 days respectively. We found that there is a statistically significant difference among three grades in post-op pain that was present on post-op day $1(<0.01)$ and $2(<0.05)$. Conclusion: There was no statistically significant difference on comparing the above variables among the three grades of appendicitis.
\end{abstract}

Key words: Laparoscopic appendicectomy, non-complicated appendicitis, complicated appendicitis

\section{Introduction}

Laparoscopic approach for surgical procedures is existing since the 1960s. The developing training and experience in the radiological and surgical instruments have facilitated in extension of this laparoscopic approach for many surgeries.

It has become the gold standard for many organs, commonest being gynaecological and digestive (as for cholecystectomy).

Appendicitis has been one of the most common cause acute surgical emergencies universally. For noncomplicated appendicitis, laparoscopic appendectomy is practised widely among all surgeons as it has been considered gold standard, due to its superiority to open
approach(OA) in terms of less postoperative pain, decreased wound infections rates, shortened hospital stay, and good overall recovery [1,2]. A Disease Severity Score (DSS) for Acute appendicitis has been formulated by a panel of acute care surgery experts.

Complicated appendicitis (Grade III, IV, V) has more morbidity and mortality than non-complicated appendicitis.

Despite of many clinical studies and meta-analyses of the various studies, it remains a confusion for the surgeons to decide which approach, whether (OA) or (LA) is the most efficacious and effective for complicated appendicitis. 
Table-1: Laparoscopic grading system of acute appendicitis [3]

\begin{tabular}{|l|l|}
\hline Grade 0 & Normal 1ooking \\
\hline Grade 1 & Redness and edema \\
\hline Grade 2 & Fibrin \\
\hline Grade 3A & Segrnental necrosis \\
\hline Grade 3B & Base Necrosis \\
\hline Grade 4A & Abscess \\
\hline Grade 4B & Regional peritomitis \\
\hline Grade 5 & Generalized peritonitis \\
\hline
\end{tabular}

This is because, the effectiveness and validity of laparoscopic approach for complicated appendicitis was doubted, as earlier studies has reported the occurrence of post-operative complication like intra-abdominal abscess [4].

Thus, in this study we desire to evaluate the safety and effectiveness of laparoscopic appendicectomy in patients with higher grades of complicated appendicitis.

\section{Patients and Methods}

Study area and setting- Department of General Surgery and Department of Emergency and Trauma care for over a period of 2 years at Chettinad Health City, Kelambakkam.

Participants- Patients presenting with clinical features of acute appendicitis

Duration of study- 2 years 2014 to 2016

Sample size- 50 patients

Study design- Prospective Cross-Sectional Study (Observational).

Inclusion criteria- Patients proven to have complicated appendicitis (Grades III, IV, V) with either radiological or by diagnostic laparoscopy

Exclusion criteria- Patients with non-complicated appendicitis (Grade I \& II).

\section{Grades of appendicitis Included}

Grade III - Segmental/ Basal Necrosis during laparoscopy

Grade IV - Abscess/ Regional Peritonitis

Grade V - Generalized Peritonitis

\section{Parameters to be assessed}

- Postoperative pain.

- Operative time.

- Laparotomy conversion rate.

- Length of hospital stay.

- Postoperative intraabdominal abscess.

- Wound dehiscence.

- Post-op ileus (Flatus passage).

\section{Criteria for Scoring system:}


Table-2 Alvarado's Score.

\begin{tabular}{|c|c|c|}
\hline \multirow[t]{3}{*}{ Symptoms } & Migratory RIF pain & 1 \\
\hline & Anorexia & 1 \\
\hline & Nausea and Vomiting & 1 \\
\hline \multirow[t]{3}{*}{ Signs } & Tenderness in RIF & 2 \\
\hline & Rebound tenderness & 1 \\
\hline & Elevated Temperature & 1 \\
\hline \multirow[t]{2}{*}{ Lab Investigations } & Leucocytosis & 2 \\
\hline & Shift to left & 1 \\
\hline \multicolumn{2}{|c|}{ Total } & 10 \\
\hline
\end{tabular}

Patients were included in this study when they have signs of complicated appendicitis, for Grade IV and V regional peritonitis/ Generalized peritonitis respectively and for Grade III patient does not have signs of peritonitis but proved to have inflamed appendix in a radiological investigation or having an Alvarado's score of 7-10 suggestive of very probable appendicitis, patient subjected for emergency diagnostic laparoscopy within 24 hours of admission. Intraoperatively if appendix found to have necrosis it will be included as Grade III and if found to have appendicular abscess it will be Included under Grade IV. After admission patient will be started on Intravenous fluids the antibiotics. Within 24 hours of admission patient were subject to Classical Three-port laparoscopic appendicectomy under general anaesthesia and their peri-operative parameters were analysed and results were established.

Statistical Methods: All data were entered in a Data Collection Performa Sheet and were entered into Excel (MS Excel 2011) and analysed using STATA statistical software package release 11 . We used the two-sided independent-samples $t$ test to compare means across dichotomous variables; the one-way ANOVA test for comparison of means across multilevel variables. Simple calculations like Percentages, Proportions and Mean values were derived. A type I error of 0.05 was considered in all analysis.

\section{Results}

In 46 patients, Laparoscopic appendicectomy was performed. And 4 patients ( $8 \%$ ) needed conversion so they were excluded from our study.

Grades of Presentations: Based on the intraoperative finding the 46 patients were graded in to three categories. Among the 46 patients of complicated appendicitis 22 patients (47.83\%) had Grade III (Gangrenous/ Perforated appendix), 15 patients (32.61\%) had Grade IV (Abscess formation) and 9 patients (19.57\%) had Grade V appendicitis.

Table-3: Grade of presentations

\begin{tabular}{|c|c|c|}
\hline Grade & N & \% \\
\hline III & 22 & 47.83 \\
\hline IV & 15 & 32.61 \\
\hline V & 9 & 19.57 \\
\hline Total & $\mathbf{4 6}$ & $\mathbf{1 0 0}$ \\
\hline
\end{tabular}

Operative time: The mean operative time for patients with complicated appendicitis undergoing laparoscopic appendicectomy was $68.8 \mathrm{mins}$.

Hospital stays- The mean length of hospital stay was found to be 3.91 days

Passage of flatus- The mean time taken for passage of flatus was 25.26 hours. The mean time taken to pass flatus was found to be 24.5 hours in grade III appendicitis, 24.5 hours in grade IV appendicitis and 28.4 hours in grade V appendicitis.

Post-operative complications- We had only one patient with Post-Operative Intra-Abdominal abscess occurrence and in none of patients we had wound infection. 


\section{Original Research Article}

Post-operative pain- Pain is an important post-operative parameter which was assessed in our study using Visual Analogue scale a pain scoring system by measuring post-operative pain in the three groups of appendicitis. Nearly half of our patients $43.47 \%$ had post-operative pain only in their first post-operative day and the second and third post-operative day it was about $34.78 \%$ and $21.73 \%$ respectively.

Table-4: Post-operative pain

\begin{tabular}{|c|c|c|}
\hline Pain & N & \% \\
\hline$<24$ hours & 20 & $43.47 \%$ \\
\hline $24-48$ Hours & 16 & $34.78 \%$ \\
\hline$>48$ hours & 10 & $21.73 \%$ \\
\hline
\end{tabular}

Table-5: Comparison of parameters within the Grades

\begin{tabular}{|c|c|c|c|c|c|c|c|}
\hline \multirow[b]{2}{*}{ Variable } & \multicolumn{2}{|c|}{ Grade III } & \multicolumn{2}{|c|}{ Grade IV } & \multicolumn{2}{|c|}{ Grade V } & \multirow[b]{2}{*}{ P Value } \\
\hline & Mean & $\mathrm{SD}$ & Mean & SD & Mean & SD & \\
\hline & 22 & & 15 & & 9 & & \\
\hline Operative time & 69.5 & 12.2 & 68.1 & 8.1 & 68.3 & 9.8 & $>0.05$ \\
\hline Hospital stay & 3.9 & 1.1 & 3.9 & 1.4 & 4.0 & 1.7 & $>0.05$ \\
\hline $\begin{array}{c}\text { Post op flatus } \\
\text { passage }\end{array}$ & 24.5 & 3.7 & 24.5 & 3.0 & 28.4 & 8.2 & $>0.05$ \\
\hline
\end{tabular}

\section{p value not significant}

Table-6: Comparison of parameters within the Grades

\begin{tabular}{|c|c|c|c|c|c|c|c|}
\hline & \multicolumn{2}{|c|}{ Grade III } & \multicolumn{2}{|c|}{ Grade IV } & \multicolumn{2}{|c|}{ Grade V } & \multirow[t]{2}{*}{ P Value } \\
\hline & $\mathrm{N}$ & $\%$ & $\mathrm{~N}$ & $\%$ & $\mathrm{~N}$ & $\%$ & \\
\hline \multicolumn{8}{|c|}{ Intra abdominal abscess } \\
\hline Absent & 22 & 100 & 14 & 93.33 & 9 & 100 & $>0.05$ \\
\hline Present & 0 & 0 & 1 & 6.67 & 0 & 0 & $>0.05$ \\
\hline \multicolumn{8}{|c|}{ Wound infection } \\
\hline Present & 0 & 0 & 0 & 0 & 0 & 0 & $>0.05$ \\
\hline Absent & 22 & 100 & 15 & 100 & 9 & 100 & $>0.05$ \\
\hline \multicolumn{8}{|l|}{ Pain } \\
\hline$<24$ & 11 & 50 & 9 & 60 & 0 & 0 & $<0.01$ \\
\hline $24-48$ & 8 & 36.36 & 2 & 13.33 & 6 & 66.67 & $<0.05$ \\
\hline$>48$ & 3 & 13.64 & 4 & 26.67 & 3 & 33.33 & $>0.05$ \\
\hline
\end{tabular}

\section{Post-operative pain}

There is a statistically significant difference among three grades in post-operative pain that was present on post-operative day one $(<0.01)$ and two $(<0.05)$.

$<24$ hours pain: $\mathrm{P}$ value $(<0.01)$ is significant.

24-48 hours pain: $\mathrm{P}$ value $(<0.05)$ is significant.

$>48$ hours pain: $\mathrm{P}$ value $(>0.05)$ is not significant.

\section{Discussion}

The management of complicated appendicitis is continuously developing over the past years. In this century, most importance is given to patients' comfort, cosmesis and a reduced hospital stay. All over the world surgeons usually preferred open approach for appendicectomy in patients with complicated appendicitis as higher grades of appendicitis was thought to be a contraindication for laparoscopic approach [3,5-7]. Some studies disagreed with this concept and compared the perioperative parameters of laparoscopic and open approaches 


\section{Original Research Article}

in complicated appendicitis $[8,9]$. On the contrary to the conventional thoughts, Laparoscopy has an overall advantage of minimizing trauma to the abdominal wall has been reproducible in many of the laparoscopic procedures compared with open surgery.

In our study of 46 patients underwent appendicectomy through laparoscopic approach, they were categorised in the grade III, IV, V. Their results were analysed and compared among the three grades of complicated appendicitis and with similar studies from literature.

Laparotomy conversion rate- In patients with complicated appendicitis, laparoscopy is a techniqually demanding procedure when compared in patients with non-complicated appendicitis [10-11]. A laparotomy conversion rate of $0 \%$ to $47 \%$ have been reported from various studies worldwide [11-16]. The rate of laparotomy conversion was lower in our study and was found to be 8 $\%(\mathrm{n}=4)$. The reason for conversion being, adhesions causing difficulty in dissection and the appendicectomy was completed after converting the procedure to open.

Operative time- The mean operative time was 68.8 Minutes (49-90 min). In almost all the studies performed on LA comparing OA they have proven that the operative time in LA was more than OA and this was basically based on the surgeon's experience and skill. In studies done to find out the efficacy of LA among various grades of complicated appendicitis like Kiriakopoulos et al [17] have reported a mean operative time of 67 minutes (4888 minutes) which was comparable with our study.

Hospital stays- We observed the mean hospital stay was 3.91 days (2- 8 days). Our results were comparable with study by Yau KK et al in which he reported mean hospital stay of 5 days for patients with complicated appendicitis undergoing LA which was statistically significant $(p<0.001)$ comparing to OA which was 6 days. Similar to the above study many studies have concluded that LA has a significantly lesser hospital stay than OA [12,18-20]

Flatus passage- The average time for post-operative ileus or flatus passage was 25.26 hours which is equivalent to a study conducted on LA in 42 complicated appendicitis patients by Kiriakopoulos et al [17] in which he reported it as 26.5 hours.

Post-operative pain- Many studies that reported the postoperative pain were lacking in a proper scoring system for post-operative pain assessment. It has been reported in various studies that LA causes very less post-operative pain than in OA. In our study, we find a statistically significant difference in post-operative pain less than 48 hours comparing the three grades of appendicitis who underwent LA. These patients were more vocal of pain although its intensity was lower. However, after third post-operative day the patients had a better sense of wellbeing and showed earlier postoperative food intake, ambulation and return to daily activities.

\section{Post-operative complications}

Intra-abdominal abscess-Of the 46 patients, we had only one patient $(2 \%)$ who has post-operative intra-abdominal abscess for which percutaneous aspiration was done and was managed with intravenous antibiotics and the patient prolonged hospital stay. Many studies have been performed to find out the intra-abdominal abscess rates like Frazee RC et al performed a prospective study on 34 patients in which he showed an intra-abdominal abscess rate of $26 \%$ and Krisher SL et al in 170 patients with complicated appendicitis he compared both Laparoscopic and open appendicectomy which he reported $24 \%$ in LA and only $4.2 \%$ in OA.[21-25]

\section{Wound infection}

Many studies have proved that wound infection following LA in complicated appendicitis is significantly low $[11,18]$ which was comparable with our study where we dint no have a single case of wound infection observed in the post-operative period. This may be because of removal of appendix with very minimal manipulation and avoiding contact with abdominal wall.

Grade III- segmental/basal necrosis/perforated- In our study, 22 patients $(47.83 \%)$ presented with grade III appendicitis in whom mean operative time was 69.5 minutes and mean hospital stay was 3.9 days. The mean time of passage of flatus in these subsets of patients was 24.5 hours and none of them had complication like Intrabdominal abscess or wound infection in the postoperative period. Our results were comparable with similar study from literature done by Kiriakopoulos et al [17] with 42 patient study group out of which 26 (61.9\%) of patients with grade III appendicitis in whom the mean operative time was 67.5 minutes and mean hospital stay was 2.8 days, the mean time of passage of flatus was 23.8 hours, but in his study, he reported one patient who had late obstruction on 3 month post-operatively.

Grade IV-abscess formation/regional peritonitis- In our study 15 patients $(32.61 \%)$ presented with grade IV appendicitis in whom mean operative time was 68.1 minutes and mean hospital stay was 3.9 days. The mean time of passage of flatus in these subsets of patients was 24.5 hours and $6.67 \%(n=1)$ of them had complication post-operative complication, intraabdominal abscess. 


\section{Original Research Article}

When comparing our results with study by Kiriakopoulos et al [17] he reported 12 patients $(9.5 \%)$ with a grade IV appendicitis in whom the mean operative time was 61.5 minutes and mean hospital stay was 3 days, the mean time of passage of flatus was 27.1 hours. Regarding the complication, he reported a case which had late obstruction in 7 months post-operatively.

Grade V-generalized peritonitis- In our study 9 patients (19.57\%) presented with grade $\mathrm{V}$ appendicitis, the mean operative time was 68.3 minutes and mean hospital stay was 4 days. The mean time of passage of flatus in these subsets of patients was 28.4hours and none of them had complication following the surgery in these group of patients. Our results were comparable with a study by Kiriakopoulos et al [17] with a study group of 42 patient out of which $28.6 \%$ had grade $\mathrm{V}$ appendicitis, in whom the mean operative time was 75 minutes and mean hospital stay was 3.8 days, the mean time of passage of flatus was 28.6 hours and however in this group no complications were reported in the postoperative period.

On comparing the operative and post-operative parameters following laparoscopic appendicectomy among the three grades of appendicitis we found that there was no statistically significant difference in operative time $(p>0.05)$, hospital stay $(p>0.05)$, Postoperative ileus ( $p>0.05)$, Intrabdominal abscess formation $(p>0.05)$, and wound infection $(p>0.05)$.

\section{Conclusion}

Though our study sample was small our results were equivalent to other studies in the literature and our study shows that laparoscopic appendicectomy is safe in various grades of complicated appendicitis patients by having less hospital stay, less post-operative flatus passage time, less post-operative pain and with very minimal post-operative infective complications like intra-abdominal abscess and wound infection. Although operative time was found to be longer, most studies find that LA is superior to OA in terms of faster recovery and less morbidity. Conversion to open was associated with higher rate of morbidities.

Hence, we find laparoscopic approach is a safe and effective for appendicectomy in all three grades of complicated appendicitis patients.

Acknowledgements: It gives me immense pleasure in submitting this publication and I thank my parents and my professors in helping me in this study.

Conflict of interest: None declared. Funding: Nil, Permission from IRB: Yes

\section{References}

1. Frazee RC, Roberts JW, Symmonds RE, Snyder SK, Hendricks JC, Smith RW, et al. A prospective randomized trial comparing open versus laparoscopic appendectomy. Annals of surgery. 1994; 219 (6):725-8; discussion 8-31.

2. Guller U, Hervey S, Purves H, Muhlbaier LH, Peterson ED, Eubanks S, et al. Laparoscopic versus open appendectomy: outcomes comparison based on a large administrative database. Annals of surgery. 2004;239 (1):43-52.

3. Gomes CA, Nunes TA, Fonseca Chebli JM, Junior CS, Gomes CC. Laparoscopy grading system of acute appendicitis: new insight for future trials. Surgical laparoscopy, endoscopy \& percutaneous techniques. 2012; 22(5):463-6.

4. Frizelle FA, Hanna GB. Pelvic abscess following laparoscopic appendectomy. Surgical endoscopy. 1996; 10(9):947-8

5. Sauerland S, Lefering $R$, Neugebauer EA. Laparoscopic versus open surgery for suspected appendicitis. The Cochrane database of systematic reviews. 2004(4):Cd001546.

6. Pokala N, Sadhasivam S, Kiran RP, Parithivel V. Complicated appendicitis--is the laparoscopic approach appropriate? A comparative study with the open approach: outcome in a community hospital setting. The American surgeon. 2007; 73 (8): 737-41; discussion 41-2.

7. Gomes CA, Junior CS, Costa Ede F, Alves Pde A, de Faria CV, Cangussu IV, et al. Lessons learned with laparoscopic management of complicated grades of acute appendicitis. Journal of clinical medicine research. 2014; 6 (4): 261-6.

8. Mancini GJ, Mancini ML, Nelson HS, Jr. Efficacy of laparoscopic appendectomy in appendicitis with peritonitis. The American surgeon. 2005; 71(1):1-4; discussion -5 .

9. Senapathi PS, Bhattacharya D, Ammori BJ. Early laparoscopic appendectomy for appendicular mass. Surgical endoscopy. 2002;16(12):1783-5.

10. Lin H-F, Lai H-S, Lai IR. Laparoscopic treatment of perforated appendicitis. World Journal of Gastroenterology : WJG. 2014;20(39):14338-47. 


\section{Original Research Article}

11. So JB, Chiong EC, Chiong E, Cheah WK, Lomanto D, Goh P, et al. Laparoscopic appendectomy for perforated appendicitis. World journal of surgery. 2002;26(12): 1485-8.

12. Yau KK, Siu WT, Tang CN, Yang GP, Li MK. Laparoscopic versus open appendectomy for complicated appendicitis. Journal of the American College of Surgeons. 2007;205(1):60-5.

13. Lin HF, Wu JM, Tseng LM, Chen KH, Huang SH, Lai IR. Laparoscopic versus open appendectomy for perforated appendicitis. Journal of gastrointestinal surgery: official journal of the Society for Surgery of the Alimentary Tract. 2006;10(6):906-10.

14. Fukami Y, Hasegawa H, Sakamoto E, Komatsu S, Hiromatsu T. Value of laparoscopic appendectomy in perforated appendicitis. World journal of surgery. 2007; 31 (1):93-7.

15. Katsuno G, Nagakari K, Yoshikawa S, Sugiyama K, Fukunaga M. Laparoscopic appendectomy for complicated appendicitis: a comparison with open appendectomy. World journal of surgery. 2009;33(2): 208-14.

16. Kirshtein B, Bayme M, Domchik S, Mizrahi S, Lantsberg L. Complicated appendicitis: laparoscopic or conventional surgery? World journal of surgery. 2007; 31(4):744-9.

17. Kiriakopoulos A, Tsakayannis D, Linos D. Laparoscopic management of complicated appendicitis. JSLS: Journal of the Society of Laparoendoscopic Surgeons / Society of Laparoendoscopic Surgeons. 2006; 10 (4):453-6.

18. Tuggle KR, Ortega G, Bolorunduro OB, Oyetunji TA, Alexander R, Turner PL, et al. Laparoscopic versus open appendectomy in complicated appendicitis: a review of the NSQIP database. The Journal of surgical research. 2010;163(2):225-8.

19. Oyetunji TA, Nwomeh BC, Ong'uti SK, Gonzalez DO, Cornwell EE, 3rd, Fullum TM. Laparoscopic appendectomy in children with complicated appendicitis: ethnic disparity amid changing trend. The Journal of surgical research. 2011;170(1): e99-103.

20. Tiwari MM, Reynoso JF, Tsang AW, Oleynikov D. Comparison of outcomes of laparoscopic and open appendectomy in management of uncomplicated and complicated appendicitis. Annals of surgery. 2011;254 (6): 927-32.

21. Strathern DW, Jones BT. Retained fecalith after laparoscopic appendectomy. Surgical endoscopy. 1999; 13(3): 287-9.

22. Bonanni F, Reed J, 3rd, Hartzell G, Trostle D, Boorse $\mathrm{R}$, Gittleman $\mathrm{M}$, et al. Laparoscopic versus conventional appendectomy. Journal of the American College of Surgeons. 1994;179(3):273-8.

23. Krisher SL, Browne A, Dibbins A, Tkacz N, Curci M. Intra-abdominal abscess after laparoscopic appendectomy for perforated appendicitis. Archives of surgery (Chicago, Ill: 1960). 2001;136(4):438-41.

24. Frazee RC, Bohannon WT. Laparoscopic appendectomy for complicated appendicitis. Archives of surgery (Chicago, Ill: 1960). 1996;131(5): 509-11; discussion 11-3.

25. Tang E, Ortega AE, Anthone GJ, Beart RW, Jr. Intraabdominal abscesses following laparoscopic and open appendectomies. Surgical endoscopy. 1996; 10 (3): 327-8.

\section{How to cite this article?}

Srigireesh A R, Natarajan R, Karunanithi R, Balakrishnan V, Loganathan M. Laparoscopic appendicectomy in higher grades of appendicitis. Surgical Update: Int J surg Orthopedics. 2017; 3(4):143-149.doi:10. 17511/ijoso.2017.i04.09. 